\title{
Profiling lethal factor interacting proteins from human stomach using T7 phage display screening
}

\author{
ALBIN CARDONA-CORREA and CARLOS RIOS-VELAZQUEZ
}

Department of Biology, College of Arts and Sciences, University of Puerto Rico-Mayagüez, Mayagüez 00681-9000, PR, USA

Received October 16, 2015; Accepted February 22, 2016

DOI: $10.3892 / \mathrm{mmr} .2016 .5031$

\begin{abstract}
The anthrax lethal factor (LF) is a zinc dependent metalloproteinase that cleaves the majority of mitogen-activated protein kinase kinases and a member of NOD-like receptor proteins, inducing cell apoptosis. Despite efforts to fully understand the Bacillus anthracis toxin components, the gastrointestinal (GI) anthrax mechanisms have not been fully elucidated. Previous studies demonstrated gastric ulceration, and a substantial bacterial growth rate in Peyer's patches. However, the complete molecular pathways of the disease that results in tissue damage by LF proteolytic activity remains unclear. In the present study, to identify the profile of the proteins potentially involved in GI anthrax, protein-protein interactions were investigated using human stomach $\mathrm{T} 7$ phage display (T7PD) cDNA libraries. T7PD is a high throughput technique that allows the expression of cloned DNA sequences as peptides on the phage surface, enabling the selection and identification of protein ligands. A wild type and mutant LF (E687A) were used to differentiate interaction sites. A total of 124 clones were identified from 194 interacting-phages, at both the DNA and protein level, by in silico analysis. Databases revealed that the selected candidates were proteins from different families including lipase, peptidase-A1 and cation transport families, among others. Furthermore, individual T7PD candidates were tested against LF in order to detect their specificity to the target molecule, resulting in $10 \mathrm{LF}$-interacting peptides. With a minimum concentration of LF for interaction at $1 \mu \mathrm{g} / \mathrm{ml}$, the T7PD isolated pepsin A3 pre-protein (PAP) demonstrated affinity to both types of LF. In addition, PAP was isolated in various lengths for the same protein, exhibiting common regions following PRALINE alignment. These findings will help elucidate and improve the
\end{abstract}

Correspondence to: Dr Carlos Rios-Velazquez, Department of Biology, College of Arts and Sciences, University of Puerto Rico-Mayagüez, 259 Blvd. Alfonso Valdez Cabian, Call Box 9000, Mayagüez 00681-9000, PR, USA

E-mail: carlos.rios5@upr.edu

Key words: lethal factor, gastrointestinal anthrax, T7 phage display, host-pathogen interactions, pepsin A, cytochrome $c$ oxidase, interleukin enhancer-binding factor 2 understanding of the molecular pathogenesis of GI anthrax, and aid in the development of potential therapeutic agents.

\section{Introduction}

Understanding the complete set of proteins targeted by bacterial toxin components, such as the anthrax lethal factor (LF), is important for the understanding of its mode of action in order to generate therapeutic agents or biomarkers. The ingestion of raw food contaminated with Bacillus anthracis spores causes gastrointestinal (GI) anthrax disease which is divided in three clinical phases: I, fainting accompanied by fever; II, abdominal pain with vomiting; and III, intensified abdominal pain accompanied with bleeding (1). Reported cases have indicated that lesions further down the GI tract, in the mid-jejunum, terminal ilium or cecum, result in single or multiple ulcerations and edema (2). In addition, a study in a mouse model for GI anthrax have suggested that the Peyer's patches is the specific site for $B$. anthracis growth following gastric inoculation (3). However, the mechanisms associated with this pathogenic bacteria in the enteric system are not well understood due to a low number of clinical cases, resulting in mortality rates of $20-60 \%$ (4). Furthermore, recent cases from India and Iran, the latter being fatal, highlight the importance of understanding the specific manifestation of GI anthrax and the administration of early treatments $(5,6)$. Therefore, it is important to understand the mode of action of this pathogenic bacteria, in particular its toxin's components.

One of the components of anthrax toxin is the LF, a zinc-dependent metalloproteinase whose entrance to the cell is through a protective antigen (PA)-mediated endocytosis (7). The LF (90 kDa) is composed of four domains: Domain I binds to the translocon PA; domain II recognizes the substrate; domain III is a duplication of a structural fragment of domain II; and domain IV contains the catalytic center (8). Once in the cell cytosol, the LF cleaves the N-terminal of mitogen-activated protein kinase kinase (MAPKK), resulting in the inhibition of the MAPK pathway (9). The MAPKKs are involved in a number of important cellular pathways including cell proliferation, embryogenesis (10) and angiogenesis (11). The disruption of these proteins promotes macrophage apoptosis due to the inhibition of p38 MAPK pathways, suggesting the requirement for $\mathrm{p} 38$ to allow the transcription of genes involved in the inhibition of apoptosis (12). Furthermore, as pathogens survive and replicate in macrophages, these cells 
undergo pyroptosis, releasing their cytosolic contents into the extracellular space (13). A previous study suggested the requirement of the direct proteolytic activity of LF on the MAPKKs for the antiproliferative and pro-apoptotic effects of the toxin at the intestinal epithelium (14). Despite the efforts to identify the LF targets in human cells, the mechanisms that cause macrophage death and the impact that it has on the innate immune response are not well understood (15).

Levinsohn et al (16) demonstrated an LF-mediated direct proteolytic cleavage at the N-terminal of NOD-like receptor protein 1 (NLRP1). This reaction yields an inflammasome response in the NLRP1B BMAJ mouse macrophage cell line. The inflammasomes are considered as the multimeric protein complexes that occur in response to danger signals within the cytoplasm and provide a scaffold for the activation of caspase-1 (17). Considering this, if an additional substrate undergoes LF-mediated cleavage, which results in apoptosis, then a novel LF-interacting partners may be suggested to promote this biological process in GI anthrax. Therefore, it is important to better understand GI anthrax at the molecular level to enable the generation of novel therapeutic agents $(18,19)$. Furthermore, identifying new anthrax LF interactions may aid in elucidating the complete pathways of the disease. The current study takes advantages of the combinatorial high throughput screening that may be performed using $\mathrm{T} 7$ phage display (PD), in order to select and identify proteins in human stomach tissue that may serve as a target to interact with LF in vitro. In addition, these observations may aid in the generation of new therapeutic agents or biosensors for the disease at the GI level.

\section{Materials and methods}

The system and methods used were based on the Novagen T7Select ${ }^{\mathrm{TM}}$ libraries procedures. Pre-made human stomach T7PD cDNA libraries (Novagen; EMD Millipore, Billerica, MA, USA), at $1.4 \times 10^{10} \mathrm{PFU} / \mathrm{ml}$, were used to perform the experiments. Two types of lethal factor were used as 'baits': Wild type (LF-WT), which has metalloproteinase activity due to a zinc dependent catalytic center on the fourth domain; and a site directed mutant in the LF active site (LF-MT) E687A, which lacks cleavage activity (20). The toxin component was purified and provided by Dr. Stephen Leppla, Laboratory of Parasitic Diseases at National Institutes of Allergy and Infectious Disease (Bethesda, MD, USA). The host strain used for T7PD screenings was an Escherichia coli Rosetta 5615 (R5615) (Novagen; EMD Millipore). These bacterial cells carry a plasmid with an ampicillin resistant gene that supplies an additional 10A capsid protein, whose expression is controlled by a lacUV5 promoter. The complete procedure was performed four times for each type of LF at four separated events of biopanning cycles. A biopanning cycle consisted of three consecutive rounds of biopanning, which was performed in the four independent experiments.

Adsorption. LF-WT and LF-MT were diluted with Tris buffered saline (TBS; Tris- $\mathrm{HCl} 10 \mathrm{mM}, \mathrm{pH} 8,150 \mathrm{mM} \mathrm{NaCl}$ ) to $4.5 \mu \mathrm{g} / \mathrm{ml}$ and transferred to sterile 96 -well polystyrene microplates (Greiner Bio-One International $\mathrm{GmbH}$, Kremsmünster, Austria) to start the LF coating. The microplate was covered with parafilm and incubated overnight at $4^{\circ} \mathrm{C}$. The microplate wells with the adsorbed target were washed three times with $300 \mu 1$ TBS to remove unbound protein. A solution of $5 \%$ casein was prepared as a blocking agent and $200 \mu \mathrm{l}$ was added to each well and incubated overnight at $4^{\circ} \mathrm{C}$. Finally, the microplate wells were washed five times with $200 \mu 1 \mathrm{TBS}$ to remove the excess blocking agent. The washed microplates were stored with $100 \mu 1$ TBS until use.

Biopanning. Aliquots of $100 \mu \mathrm{l}$ containing $\sim 1.4 \times 10^{7}$ clones of the stomach T7PD cDNA library were applied to the coated wells to initiate the protein-protein interactions. The microplates were incubated for $1 \mathrm{~h}$ at room temperature. To remove phages expressing non-interacting peptides, five stringent washes were performed using $200 \mu \mathrm{l}$ TBS with $0.2 \%$ Tween 20 (TBST). Phage particles with specific binding properties to the target were eluted using $200 \mu \mathrm{l} 1 \%$ sodium dodecyl sulfate (SDS). The bioamplification of the LF interacting partners was performed by infection with a previously induced R5615 with isopropyl- $\beta$-D-thiogalacto pyranoside (Sigma-Aldrich, St. Louis, MO, USA) at $1 \mathrm{mM}$. Subsequently, the purification of the phage particles was performed by centrifuging $1,500 \mu \mathrm{l}$ of the lysed culture at $8,000 \mathrm{x} \mathrm{g}$ for $10 \mathrm{~min}$ at room temperature, following which the supernatant was transferred to a clean tube. The biopanning product (supernatant) was used to perform the second selection round by adding aliquots of $100 \mu \mathrm{l}$ containing $\sim 1 \times 10^{7}$ clones to each well. A third biopanning round was conducted using aliquots of $100 \mu \mathrm{l}$ containing $\sim 1 \times 10^{9}$ clones from the product of the second round, in order to promote specificity and reduce random interactions (Fig. 1).

Overlay assay and polymerase chain reaction (PCR). A series of dilutions (from $10^{2}-10^{10}$ ) of the phage lysates were performed in order to quantify the number of amplified phages following the third round of biopanning. Selected dilutions $\left(10^{6}-10^{7}\right)$ were mixed with a fresh culture of R5615 (OD 600 0.5) on top agar [Luria Bertani (LB; Difco Laboratories, Inc., Detroit, MI, USA) broth $0.7 \%$ agar]. The mix was transferred to a petri dish, containing bottom agar (LB agar with $50 \mu \mathrm{g} / \mathrm{ml}$ ampicillin). The plates were incubated at $37^{\circ} \mathrm{C}$ until plaques were observed. Following phage quantification, plaques were extracted and transferred to a clean tube with fresh induced R5615 culture. Once the phage particles were isolated, their DNA was extracted. The amplification of the cloned cDNA was performed by PCR using GoTaq Green Master Mix (Promega Corporation, Madison, WI, USA), following the manufacturer's instructions. The amplification reaction was performed as follows: $10 \mathrm{pmol}$ of each PD cloning site specific primer T7Select forward 5'-GGAGCTGTCGTATTCCAGTC-3' and T7Select reverse 5'-GCTGATACCACCCTTCAAG-3' (Novagen; EMD Millipore). A total of 1-2 $\mu \mathrm{l}$ of phage lysate was used as the template DNA. All the PCR reactions were performed with a total volume of $25 \mu 1$.

The thermal cycler (T100; Bio-Rad Laboratories, Inc., Hercules, CA, USA) conditions consisted of an initial denaturation step at $94^{\circ} \mathrm{C}$ for $3 \mathrm{~min}$, followed by 30 cycles of $94^{\circ} \mathrm{C}$ for $30 \mathrm{sec}, 51^{\circ} \mathrm{C}$ annealing for $30 \mathrm{sec}, 72^{\circ} \mathrm{C}$ extension for $30 \mathrm{sec}$, and a final extension at $72^{\circ} \mathrm{C}$ for $6 \mathrm{~min}$. The PCR 
A

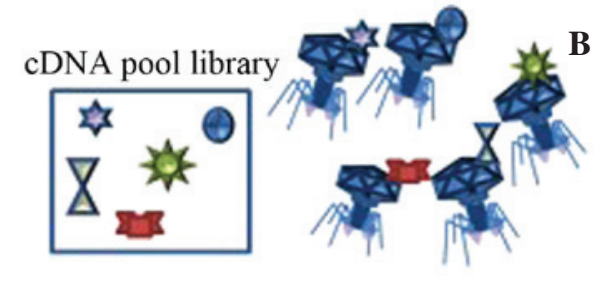

Population of protein

variants expressed in

phage T7 capsid

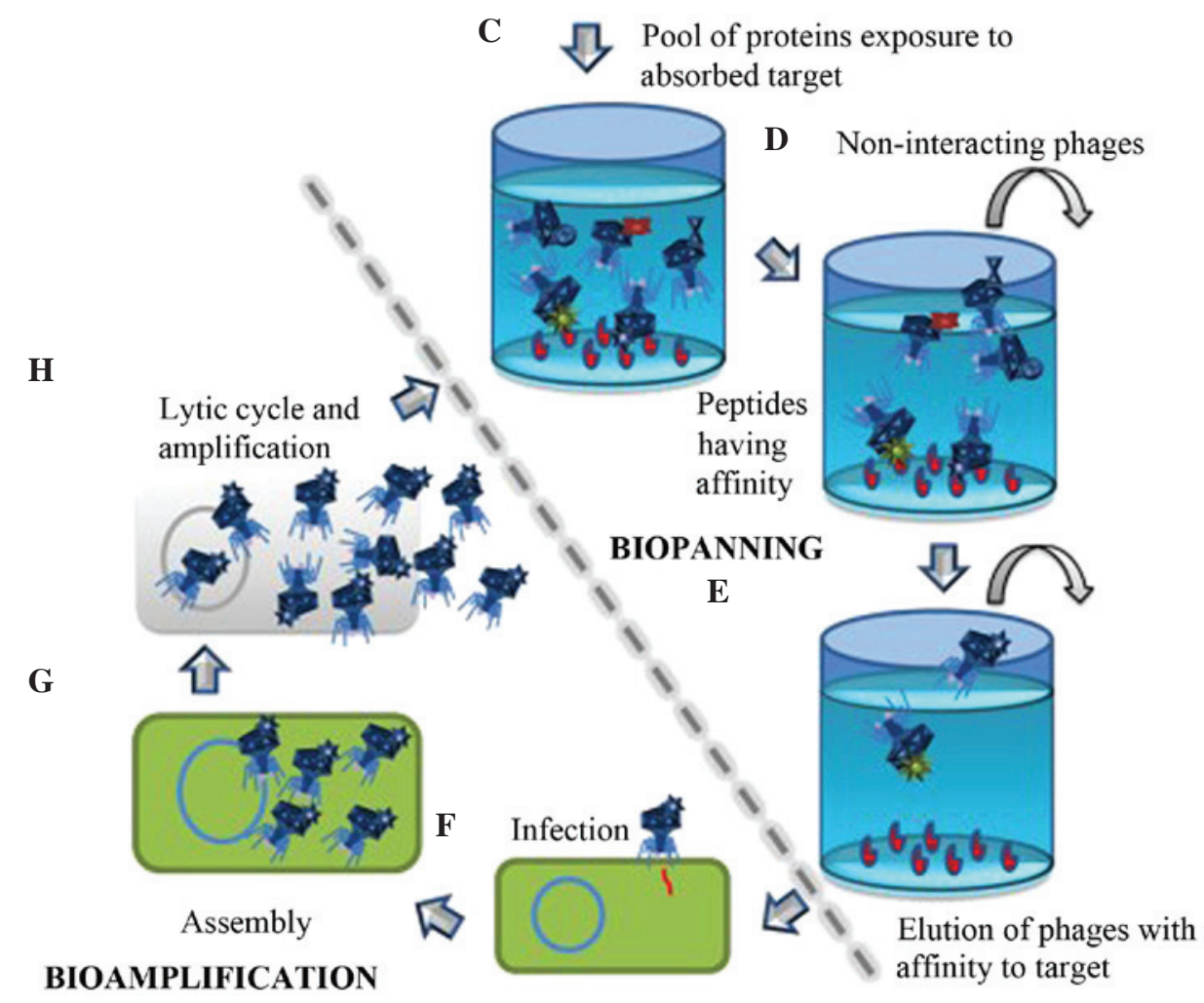

Figure 1. Biopanning and bioamplification process. (A) Pool of human stomach T7PD cDNA library. (B and C) Dilution of phage library and protein-protein interactions step. (D) Stringent washes using buffers were performed in order to discard clones expressing peptides with low or random affinity to LF. (E) Elution of phage particles with specific binding properties to LF. (F) Infection of Escherichia coli Rosetta5615. (G) Amplification and assembly of phage T7. (H) Lytic step, phages are released outside the host cell. T7PD, T7 phage display; LF, anthrax lethal factor.

control reactions were prepared to compare the experimental results. PCR control reactions consisted on a known and already amplified PD clone DNA sample (positive control) and a reaction tube without DNA sample (negative control). A $1.8 \%$ agarose gel (Denville Scientific, Inc., South Plainfield, NJ, USA) was run, using a horizontal electrophoresis unit to confirm the presence of amplicons. For this step, $1 \mathrm{X}$ Tris-acetate-EDTA was used as running buffer, and the gel was analyzed using a Gel Documentation system (Bio-Rad Laboratories, Inc.). The amplicons were sent to MCLAB (San Francisco, CA, USA) for sequencing. Sequences were refined using BioEdit 7.2.5 (Ibis Biosciences, Carlsbad, CA, USA). The DNA was translated to amino acid sequences using the bioinformatics web tool Expasy (http://web. expasy.org/translate/; SIB Swiss Institute of Bioinformatics, Lausanne, Switzerland). The DNA and protein sequences were analyzed using the National Center for Biotechnology Information BLAST ${ }_{\mathrm{N}} / \mathrm{p}$ for human species, with this program able to compare sequence homologies (21).

Specificity test and minimum concentration for interaction (MCI). The LFs (WT \& MT) were immobilized on 96-well microplates at $22.5 \mu \mathrm{g} / \mathrm{ml}$. All the biopannings were performed using 5\% casein as blocking agent. If the specificity test revealed interaction of the T7PD candidates with casein, the blocking agent was then changed to $3 \%$ bovine serum albumin, and the specificity test repeated. Individual phages expressing selected peptides were exposed to experimental wells and empty wells that contained only blocking agents. Following five washes with TBST, and an elution using 1\% SDS, the product of interactions $(\sim 400 \mu \mathrm{l})$ was inoculated on $5 \mathrm{ml}$ cultures of R5615. The cultures were incubated at $37^{\circ} \mathrm{C}$ for $4 \mathrm{~h}$ or until lysis was detected. For the MCI assay, the LFs (WT \& MT) at 1,2 and $3 \mu \mathrm{g} / \mathrm{ml}$ were adsorbed onto microplate wells. To test the MCI, an individual candidate that showed affinity to both types of LF was used for this test. The candidate was exposed to the LFs following the biopanning protocols. The elution product from the wells was inoculated on R5615 $5 \mathrm{ml}$ cultures, which were then incubated at $37^{\circ} \mathrm{C}$ until lysis was detected. For both assays the $\mathrm{OD}_{600}$ readings were measured using the Eppendorf UV biophotometer (Eppendorf, Hamburg, Germany). The OD readings were utilized to identify the lysis of the bacteria vs. the control (data not shown). 
Table I. Candidates that showed putative affinity to LF following the T7 phage display specificity test.

\begin{tabular}{|c|c|c|c|}
\hline Peptide similarity & 'Bait' & Peptide sequence & Type of blocking agent \\
\hline $\begin{array}{l}\text { Pepsin A3 } \\
\text { preprotein }\end{array}$ & $\begin{array}{l}\text { LF-MT } \\
\& \text { WT }\end{array}$ & $\begin{array}{l}\text { ACISGFQGMNLPTES } \\
\text { GELWILGDVFIRQYFT } \\
\text { VFDRANNQVGLAPVA }\end{array}$ & NL B \\
\hline $\begin{array}{l}\text { Pepsin A } \\
\text { preprotein }\end{array}$ & LF-MT & $\begin{array}{l}\text { ASSYYTGSLNWVPVTVEGH } \\
\text { WQITVDSITM NGEAIACAE } \\
\text { GCQAIVDTGTSLLTGPTSPIA } \\
\text { NIQSDIGASENSDGDMV } \\
\text { VSCSAISSLPDIVFTINGVQYPV } \\
\text { PPSAYILQ SEGSCISGFQGMNL } \\
\text { PTESGELWILGDVFIR QY } \\
\text { FTVFDRANNQVGLAPVA }\end{array}$ & $\begin{array}{c}+\mathrm{C} \\
\mathrm{NLC} / \mathrm{T}\end{array}$ \\
\hline $\begin{array}{l}\text { Gastric triacylglycerol } \\
\text { lipase }\end{array}$ & ND & $\begin{array}{l}\text { ANVTAMNVPIAVWNGGKDP } \\
\text { LADPQDVGLLLPKLPNL } \\
\text { IYHKEIPFYNHLDFIWAMDA } \\
\text { PQEVYNDIVSMISEDKK }\end{array}$ & $\begin{array}{l}+\mathrm{C} / \mathrm{T} \\
+\mathrm{B}\end{array}$ \\
\hline $\begin{array}{l}\text { Interleukin enhancer- } \\
\text { binding factor } 2\end{array}$ & LF-WT & $\begin{array}{l}\text { AVTPSEKAYEKPPEKKE } \\
\text { GEEEEENTEEPPQGE } \\
\text { EEESMETQE }\end{array}$ & NL C \\
\hline $\begin{array}{l}\text { Copper transporting } \\
\text { ATPase }\end{array}$ & LF-WT & $\begin{array}{l}\text { AREQGQDLHTP } \\
\text { LGRTVRRIRYI }\end{array}$ & NL C \\
\hline $\begin{array}{l}\text { Probable phospholipid } \\
\text { ATPase }\end{array}$ & LF-WT & ALLTYWENSLC & NL C \\
\hline $\begin{array}{l}\text { Cytochrome } c \\
\text { oxidase }\end{array}$ & LF-WT & $\begin{array}{l}\text { AELGQPGNLLGNDHI } \\
\text { YNVIVTAHAFVIIF } \\
\text { FIVIPIIIGGFGN }\end{array}$ & NLC \\
\hline $\begin{array}{l}\text { Death ligand } \\
\text { signal enhancer }\end{array}$ & LF-MT & ALEFKPSTASSTGCRSGQW & NLC \\
\hline $\begin{array}{l}\text { GDNF-inducible } \\
\text { zinc finger protein } 1\end{array}$ & $\begin{array}{l}\text { LF-MT \& } \\
\text { WT }\end{array}$ & LNLVIVQVSSGPGVSSAPA & NL C \\
\hline $\begin{array}{l}\text { Homo sapiens chromosome } \\
11 \text { open reading frame } 96\end{array}$ & $\begin{array}{l}\text { LF-MT } \\
\& \text { WT }\end{array}$ & $\begin{array}{l}\text { AECWRECEWVCAG } \\
\text { GHGGAVCKIGVANHRT } \\
\text { RAWSGYPPPTQRGRASPH } \\
\text { TLTAEFALGRVKKA }\end{array}$ & NL C \\
\hline
\end{tabular}

LF-MT, lethal factor-mutant; LF-WT, LT-wild type; B, 3\% BSA; +, lysed cultures; NL, no lysis detected; C, 5\% casein; C/T, increase in Tween 20 using casein; ND, interaction was not determined; GDNF, glial cell-derived neurotrophic factor.

In silico analysis of LF-interacting partners. Multiple sequence alignments and the hydrophobicity of peptides that showed putative affinity to LF in vitro were determined using the Centre for Integrative Bioinformatics PRALINE web tools (http://www.ibi.vu.nl/programs/pralinewww/) (22). Default parameters were used for this analysis. The full-length reference sequences for peptides with conserved amino acids used for comparisons were obtained from Uniprot databases.

\section{Results}

Selection and DNA isolation. Following four different rounds of selection, through the three rounds of biopannings a total of 192 interacting phages were isolated and amplified. A total of 124 putative LF-interacting clones were amplified by PCR and verified in a $1.8 \%$ agarose gel. The total number of identified clones for LF-WT was 54. In addition, a total of 70 clones were identified as LF-MT interacting partners. Amplicon size varied from 300-1,000 base pairs in the majority of cases for both types of LF (Fig. 2).

Identification of candidates. Following the sequencing of the 124 clones, a total of 84 were selected for the present study, and after the in silico analysis, 33 different known human proteins were identified. From these proteins, $60 \%$ demonstrated interaction with LF-MT, and 36\% with LF-WT. Furthermore, $9 \%$ of the identified proteins were obtained when either type of LF was used as bait. In general, the LF-MT interacting partners were predominantly associated with the peptidase A1, lipase gastric, and kruppel $\mathrm{C} 2 \mathrm{H} 2$-type zinc-finger protein (ZNF) families. By contrast, proteins identified for LF-WT belonged predominantly to the 


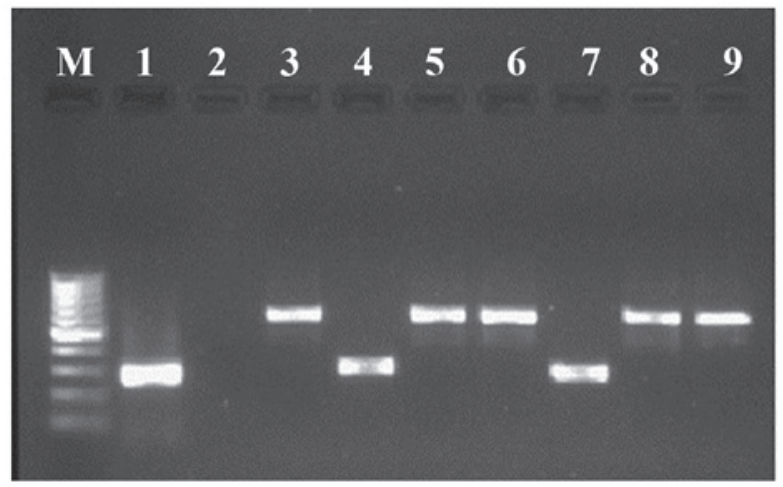

Figure 2. Amplicons verified by an electrophoresis gel (1.8\% agarose) indicated that the fragments of cDNA varied from 300-1,000 base pairs. The DNA size was determined using a 100-bp marker (lane M). Lane 1, positive control; lane 2, negative control; lanes 3-9, sample exposed to polymerase chain reaction consisting only of master mix without DNA template. M, marker.

A

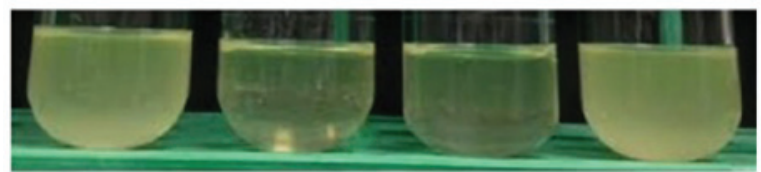

B

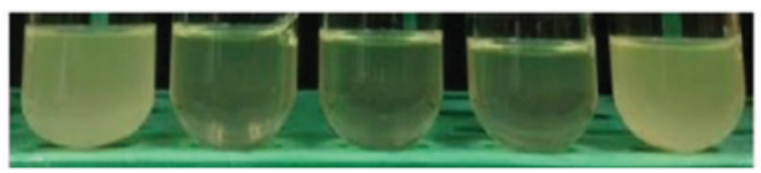

Figure 3. Specificity test and minimum concentration for interaction results. The tubes represent the $E$. Coli R5615 cultures combined with the eluted interaction products (T7PD candidates) to the baits (LF-MT and LF-WT), using different blocking agents ( $5 \%$ casein or $3 \%$ bovine serum albumin) Tubes with cloudy appearance (high turbidity) imply active growth of R5615 due to the lack of interacting phages. Clear tubes suggest bacterial lysis produced by the presence of phages in the elution products, demonstrating interaction with the respective baits. (A) Image shows (from left to right): $5 \mathrm{ml}$ cultures of R5615 exposed to the interaction elution product of an untreated well; those with LF-mutant and LF-wild type; and one exposed to the product of BSA interaction. (B) Image shows (from left to right): $5 \mathrm{~m}$ cultures of R5615 exposed to untreated well product of interaction; to the elution of $1 \mu \mathrm{g} / \mathrm{ml} \mathrm{LF}$ wells; $2 \mu \mathrm{g} / \mathrm{ml} \mathrm{LF}$ wells; $3 \mu \mathrm{g} / \mathrm{ml} \mathrm{LF}$ wells; and the product from a BSA based test. LF, lethal factor; BSA, bovine serum albumin.

peptidase A1 family. In addition, proteins associated with DNA binding, antigen recognition and the cell cycle were identified. The proteins that interacted with both types of LF were pepsin A, gastric triacylglycerol lipase and a ribosomal protein.

The distribution of the isolated clones following the biopanning was $\sim 12 \%$ related to the peptidase A1 family, $7 \%$ Kruppel and $6 \%$ to the abhydrolase family. The remaining clones had lower frequencies per family. Furthermore, the in silico analysis revealed conserved domains, including abhydrolase 1, aspartyl proteases, xylanase inhibitors and BRICHOS. These domains correspond to the proteins gastric lipase (GL), pepsin A, gastricsin and gastrokine-1, respectively. The remaining proteins did not show putative conserved domains or motifs. The size of the three largest peptides consisted of 170 amino acids (aa) (gastricsin), 156aa (pepsin A) and 122aa (A kinase anchor protein) residues. The smallest peptide (5aa) identified in silico, shared similarity with Ras-related protein Rab-34.
Specificity test and MCI. Following the specificity test a total of 10 proteins (Table I) were observed to interact with a minimum of one type of LF. Of these, two were specific to LF-MT, four to LF-WT and three showed affinity to both types of targets tested. The $10^{\text {th }}$ protein (Gastric lipase) demonstrated an inconclusive affinity to LF due to its ability to interact with multiple baits and all the blocking agents used. The GL candidate interaction remains poorly understood due to its affinity to the blocking agents. In Fig. 3A, an example of the lysis detection for this test is presented. As the pepsin A3 pre-protein (46aa in length) showed affinity to both types of LF in vitro, this candidate was used to determine the MCI. For both targets used the required concentration of LF to allow interactions was detected at $1 \mu \mathrm{g} / \mathrm{ml}$ (Fig. 3B).

Multiple sequence alignment and hydrophobicity scale. From all the putative LF-interacting partners, the peptide sequences corresponding to pepsin A exhibited regions in common following PRALINE alignment (Fig. 4). These clones were identified in different biopanning events, and the peptides varied in size. The detected peptides belongs to the pepsin A (EC:3.4.23.1).

The identity coverage in the putative pepsin PD clones compared with the reference sequence protein range from 15-20\%. The hydrophobicity analysis using PRALINE indicated that the remaining identified peptides consist mostly of hydrophilic residues (data not shown). However, several hydrophobic regions were detected.

\section{Discussion}

Currently, the identified targets that undergo direct cleavage by LF belong to protein families such as NLRPs and MAPKKs $(23,24)$. However, the mechanisms involved in GI anthrax infection are not well known (25), meaning that the toxin components targets remain to be identified. In the current study, a number of proteins are suggested to be putative LF targets through the T7PD technique. The data suggest a more diverse group of proteins have affinity to the LF-MT than the LF-WT. This may be due to the mutated catalytic center in LF-MT. Having no metalloproteinase activity enables the selection and identification of interacting proteins with the protease domain, however, avoiding the cleavage of the protein 


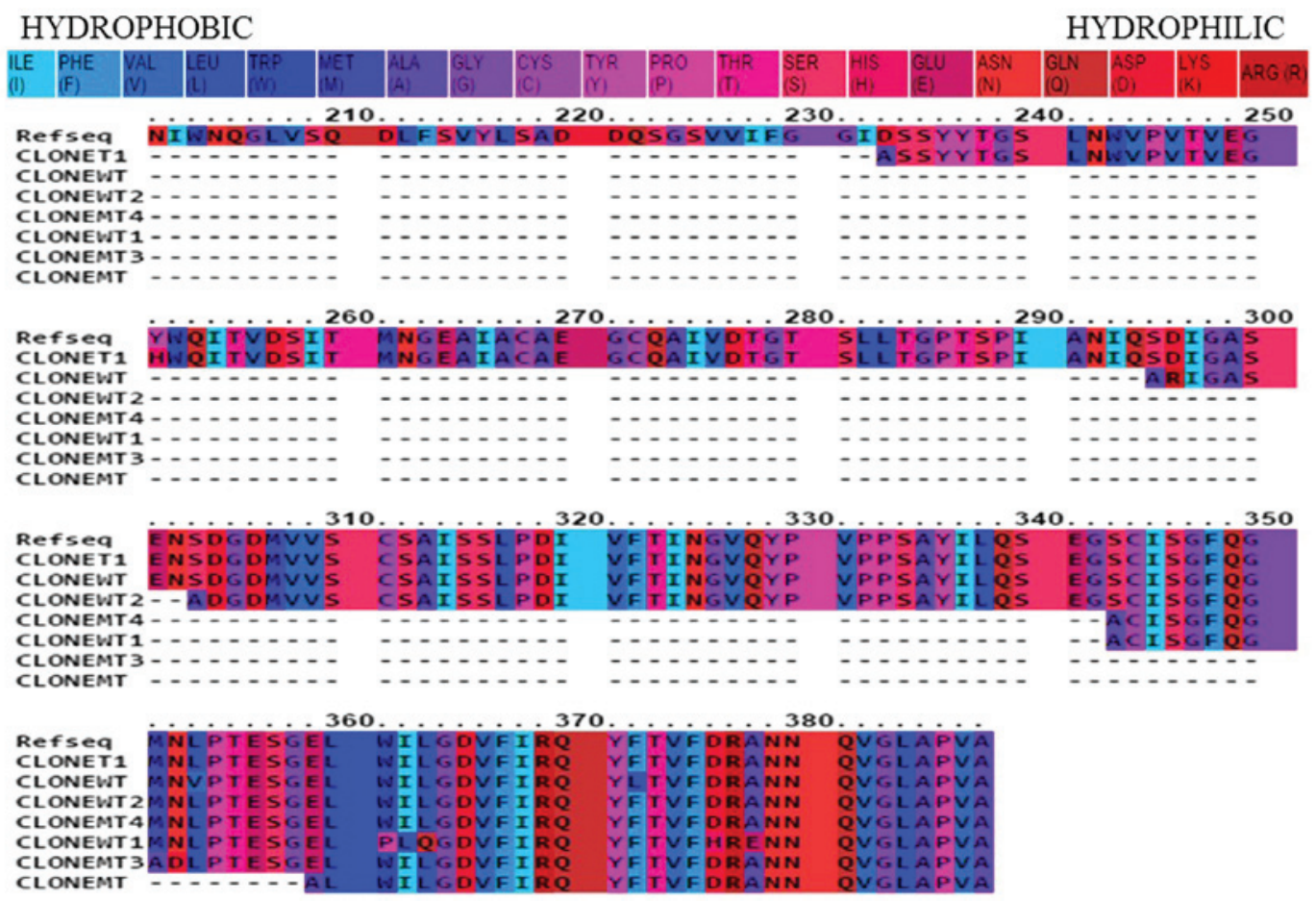

Figure 4. PRALINE alignment and hydrophobicity scale for peptides that belong to pepsin A preprotein. The clones match with the C-terminus of the full length reference protein. The pepsin clones additionally showed conserved amino acids within the C-terminus of the full length reference protein (EC:3.4.23.1). Alternating pockets of hydrophobic and hydrophilic amino acids indicated. Certain peptide sequences are not present in Table I to avoid redundancy. WT, wild type; MT, mutant.

and the loss of valuable data following the washing steps. Following the in silico analysis, the same putative interacting partners for LF-MT and LF-WT were identified, for example, GL and pepsin A preprotein. Therefore, proteins such as GL and pepsin A preprotein may be interacting with domains II and III of LF as they were present in both types of LF tested. As reported by Pannifer et al (8), these domains are involved in the recognition of substrate by the metalloproteinase. For this reason, any interactions between the substrate recognition domains and human stomach proteins were able to be detected by PD. However, isolation from PD using LF-WT as bait was possible due to multiple interactions with a non-catalytic region of LF (e.g. domains II and III). However, despite GL being a constant candidate isolated through the biopanning cycles, the interactions of this candidate with LF were not determined. This candidate showed promiscuous interaction properties, being considered as a possible non-specific LF interacting peptide.

The putative conserved domains obtained (Fig. 4) may represent a step towards understanding GI anthrax. The detection at independent events, following all biopanning cycles, of proteins having affinity for LF-WT and LF-MT, such as the gastric triacylglycerol lipase and pepsin A, represent the most valuable candidates. This data suggests that both sequences may have interactions with the LF at least in vitro. For pepsin A, a member of the peptidase A1 protein family, the minimum conserved sequence for being a LF-interacting partner isolated by PD was of 30 residues that matches with the aspartyl protease domain. Several members from different peptidase families have been proposed as anthrax LF inhibitors, resulting in the survival of macrophage cells due to an interference of LF protease activity (26). The pepsins are well known to have a preference for hydrophobic ligands, and some of these may serve as inhibitors, such as pepstatin (27). Considering this, the interactions between the hydrophobic residues presented in Fig. 3 and the hydrophobic amino acids from domain III proposed by Pannifer et al (8) may explain and support our data. The largest peptide identified in the present study was gastricsin, which belongs to the peptidase A1 family. This contained domains that belong to aspartyl protease and xylanase inhibitors, and did not have considerable conserved regions with pepsin $\mathrm{A}$, suggesting that the protease domain may be recognizing LF. As a result, peptides from this protein family may be tested in order to identify potential as LF inhibitors.

A previous study established an association between the MAPKK stress signaling pathways and time, as an explanation of the alteration of these proteins in in vivo models, however, not in vitro (28). The same study suggested a difference in the regulation of these proteins during stress conditions. For this reason, the duration of interactions may have served an important role in the identified interactions, explaining the absence of these proteins in the current study. An alternative explanation may be that due to the presence of low abundance mRNA for this protein in the stomach, compared with other tissues (29). However, stomach MAPKK's levels are comparable to other tissues, which could be due to high stability of these proteins. Considering that human stomach cDNA libraries are generated using mRNAs, this may explain the non-isolation and identification of the MAPKKs. In the current study, proteins from different families were identified as putative LF-binding partners, however, not at the high frequency as the previously 
mentioned ones. These proteins were confirmed through a specificity test, consisting of exposing individual candidates to LF and to the blocking agent individually.

The interleukin enhancer-binding factor 2 peptide consisted predominantly of hydrophilic residues. The group of interleukin enhancers, such as interleukin 2 (IL-2), have the property of binding to antigen receptors (30). Previous studies suggested IL-2 inhibition due to the LF-mediated disruption of the MAPKK pathway (31). Therefore, the present study proposes a possible alternate route for the inhibition of IL-2 as an immune response during anthrax disease. Two additional isolated peptides were part of the P-type ATPases and showed putative affinity to LF. P-type ATPases are considered as anion, cation and lipid pumps located in cell membranes; these enzymes generate electrochemical gradients using metabolic energy and additionally mediate cell signaling pathways (32). Due to their ability to maintain homeostasis through the transport of different ions such as $\mathrm{Ca}^{2+}$, the lack of activity from these enzymes can result in neurological disorders (33). Accordingly, the disruption of these ion pumps may result in an electrochemical imbalance within the cell, and potentially promote the circulatory shock stage in patients with GI anthrax. A previous study of cardiomyocytes infected with the anthrax lethal toxin indicated disruption of their function and of the intracellular calcium transport; however, the underlying mechanism is not clear (28).

An additional LF-interacting partner isolated through T7PD was cytochrome $c$ oxidase $(\mathrm{CcO}) . \mathrm{CcO}$ is a metalloprotein that maintains the proton gradient and synthesis of ATP, and in addition activates oxygen as the terminal acceptor of the transport electron chain (34). A previous study postulated that $\mathrm{CcO}$ and additional proteins involved in energy pathways were inactivated in macrophages via an s-nitrosylation process, driven by $B$. anthracis-derived nitric oxide, resulting in cell death (35). While the net charge of the T7PD isolate similar to $\mathrm{CcO}$ is neutral, it is possible that the interaction with $\mathrm{LF}$ is due to a hydrophobic region present in the peptide. These results suggest a possible inhibition of $\mathrm{CcO}$, followed by its release, through the proteolytic activity of LF in GI anthrax, resulting in a reduction in the efficiency of cellular respiration. The identified death ligand enhancer (DELE) is known to be involved in apoptosis by activating tumor necrosis factor (TNF)- $\alpha$ and TNF-related apoptosis-inducing ligand; however, this process is due to the binding of death associated protein (DAP3) to DELE (36). The same study additionally suggested that the disruption of DELE reduced the rate of apoptosis in cells; therefore the in vitro interaction between DELE and LF is unclear. This may be due to LF altering the conformation of DELE, increasing its affinity for DAP3, followed by the rest of the apoptosis signaling pathways.

Glial cell-derived neurotrophic factor (GDNF) zinc finger protein was suggested as a transcriptional repressor of HOXA10 gene, which is associated with morphogenesis (37). The ZNFs are considered as residues of cysteine and histidine, whose center binds zinc and provides structural stability to the rest of the protein in order to allow interactions with DNA (38). These protein motifs are known to be involved in the transcriptional process. The amino acid sequences for these motifs varied in length from 20-22aa and were identified as the mutant-interacting partners. Despite the identification of two types of ZNFs, including the GDNF, further studies are required in order to understand the origin of these motifs.

The mechanisms of GI anthrax are poorly understood due to the deficit of in vivo models of the disease (39). Burgos (40) suggested that the use of T7PD to determine LF-binding proteins from different human tissues revealed the presence of proteins including cytochrome $c$ oxidase, ribosomal proteins and ATPase. This supports the data of the current study, and indicates the identity of the profile of proteins involved in GI anthrax, and aids in the understanding of how this pathogenic bacteria evades the immune system, breaks down epithelial barriers and its dissemination out from the GI system.

Through T7PD, the present study provided a profile of potential proteins from the human stomach that binds LF. Further studies both in vitro and in vivo are necessary in order to confirm and understand the complete set of events that promote tissue death, and the identity of proteins cleaved by the metalloproteinase LF, resulting in apoptosis. The generation of in vivo models will serve to determine which of the reported proteins are cleaved by the anthrax LF. Additionally, considering the constant in vitro interactions in the present study, these highly conserved peptides may be synthesized and tested as inhibitors in in vivo assays. In conclusion, the use of T7PD in the present study is a platform from which to begin unraveling GI anthrax at the molecular level, to elucidate the disease pathways and generate novel therapeutic agents.

\section{Acknowledgements}

The authors would like to thank Dr Stephen Leppla for providing the purified LF, and for his comments and suggestions on the manuscript. The current study was supported by a Enhancing Biomedical Sciences and Biomedical Engineering in Science and Technology (RISE2BEST) grant (grant no. NIH-R25GM088023), from the National Institute of General Medical Sciences. The authors would also like to thank Miss Lorein Moya for her assistance with the specificity test analysis. The present study was previously presented at the 115th Annual Meeting of the American Society for Microbiology in New Orleans, Louisiana, USA.

\section{References}

1. Akbulut A, Akbulut $H$, Özgüler $M$, İnci $N$ and Yalçın S: Gastrointestinal anthrax: A case and review of literature. Adv Infect Dis 2: 67-71, 2012.

2. Sirisanthana T and Brown AE: Anthrax of the gastrointestinal tract. Emerg Infect Dis 8: 649-651, 2002.

3. Glomski IJ, Piris-Gimenez A, Huerre M, Mock M and Goossens PL: Primary involvement of pharynx and peyer's patch in inhalational and intestinal anthrax. PLoS Pathog 3: e76, 2007.

4. Tonry JH, Popov SG, Narayanan A, Kashanchi F, Hakami RM, Carpenter $\mathrm{C}$, Bailey $\mathrm{C}$ and Chung $\mathrm{MC}$ : In vivo murine and in vitro M-like cell models of gastrointestinal anthrax. Microbes Infect 15: 37-44, 2013.

5. Iqbal N, Basheer A, Ramesh AN, Vimal J, Mookkappan S, Kanungo R, Anandhalakshmi and Princess I: Gastrointestinal anthrax in coastal south India: A critical alert on a fatal masquerader. JMM Case Rep 2: e0.000013, 2015.

6. Hashemi SA, Azimian A, Nojumi S, Garivani T, Safamanesh S and Ghafouri M: A case of fatal gastrointestinal anthrax in north eastern Iran. Case Rep Infect Dis 2015: 875829, 2015.

7. Bouzianas DG: Medical countermeasures to protect humans from anthrax bioterrorism. Trends Microbiol 17: 522-528, 2009. 
8. Pannifer AD, Wong TY, Schwarzenbacher R, Renatus M, Petosa C, Bienkowska J, Lacy DB, Collier RJ, Park S, Leppla $\mathrm{SH}$, et al: Crystal structure of the anthrax lethal factor. Nature 414: 229-233, 2001

9. Duesbery NS, Webb CP, Leppla SH, Gordon VM, Klimpel KR, Copeland TD, Ahn NG, Oskarsson MK, Fukasawa K, Paull KD and Vande Woude GF: Proteolytic inactivation of MAP-kinase-kinase by anthrax lethal factor. Science 280: 734-737, 1998

10. Pearson G, Robinson F, Beers Gibson T, Xu BE, Karandikar M, Berman K and Cobb MH: Mitogen-activated protein (MAP) kinase pathways: Regulation and physiological functions. Endocr Rev 22: 153-183, 2001.

11. Yang J, Boerm M, McCarty M, Bucana C, Fidler IJ, Zhuang Y and Su B: Mekk3 is essential for early embryonic cardiovascular development. Nat Genet 24: 309-313, 2000.

12. Park JM, Greten FR, Li ZW and Karin M: Macrophage apoptosis by anthrax lethal factor through p38 MAP kinase inhibition. Science 297: 2048-2051, 2002.

13. Miao EA, Rajan JV and Aderem A: Caspase-1-induced pyroptotic cell death. Immunol Rev 243: 206-214, 2011.

14. Sun C, Fang H, Xie T, Auth RD, Patel N, Murray PR, Snoy PJ and Frucht DM: Anthrax lethal toxin disrupts intestinal barrier function and causes systemic infections with enteric bacteria. PloS One 7: e33583, 2012.

15. Liu S, Moayeri M and Leppla SH: Anthrax lethal and edema toxins in anthrax pathogenesis. Trends Microbiol 22: 317-325, 2014.

16. Levinsohn JL, Newman ZL, Hellmich KA, Fattah R, Getz MA Liu S, Sastalla I, Leppla SH and Moayeri M: Anthrax lethal factor cleavage of Nlrpl is required for activation of the inflammasome. PLoS Pathog 8: e1002638, 2012.

17. Moayeri M, Sastalla I and Leppla SH: Anthrax and the inflammasome. Microbes Infect 14: 392-400, 2012

18. Lightfoot YL, Yang T, Sahay B, Zadeh M, Cheng SX, Wang GP, Owen JL and Mohamadzadeh M: Colonic immune suppression, barrier dysfunction and dysbiosis by gastrointestinal Bacillus anthracis infection. PloS One 9: e100532, 2014.

19. Baldari CT, Tonello F, Paccani SR and Montecucco C: Anthrax toxins: A paradigm of bacterial immune suppression. Trends Immunol 27: 434-440, 2006.

20. Klimpel KR, Arora N and Leppla SH: Anthrax toxin lethal factor contains a zinc metalloprotease consensus sequence which is required for lethal toxin activity. Mol Microbiol 13: 1093-1100, 1994.

21. Altschul SF, Gish W, Miller W, Myers EW and Lipman DJ: Basic local alignment search tool. J Mol Biol 215: 403-410, 1990 .

22. Pirovano W, Feenstra KA and Heringa J: PRALINETM: A strategy for improved multiple alignment of transmembrane proteins. Bioinformatics 24: 492-497, 2008

23. Hellmich KA, Levinsohn JL, Fattah R, Newman ZL, Maier N, Sastalla I, Liu S, Leppla SH and Moayeri M: Anthrax lethal factor cleaves mouse nlrplb in both toxin-sensitive and toxin-resistant macrophages. PLoS One 7: e49741, 2012.

24. Vitale G, Pellizzari R, Recchi C, Napolitani G, Mock M and Montecucco C: Anthrax lethal factor cleaves the N-terminus of MAPKKs and induces tyrosine/threonine phosphorylation of MAPKs in cultured macrophages. Biochem Biophys Res Commun 248: 706-711, 1998.
25. Bishop BL, Lodolce JP, Kolodziej LE, Boone DL and Tang WJ: The role of anthrolysin $\mathrm{O}$ in gut epithelial barrier disruption during Bacillus anthracis infection. Biochem Biophys Res Commun 394: 254-259, 2010

26. Menard A, Papini E, Mock M and Montecucco C: The cytotoxic activity of Bacillus anthracis lethal factor is inhibited by leukotriene A4 hydrolase and metallopeptidase inhibitors. Biochem J 320: 687-691, 1996.

27. Kuzmič P, Sun CQ, Zhao ZC and Rich DH: Long range electrostatic effects in pepsin catalysis. Tetrahedron 47: 2519-2534, 1991.

28. Kandadi MR, Hua Y, Ma H, Li Q, Kuo SR, Frankel AE and Ren J: Anthrax lethal toxin suppresses murine cardiomyocyte contractile function and intracellular $\mathrm{Ca} 2+$ handling via a NADPH oxidase-dependent mechanism. PloS One 5: e13335, 2010.

29. Uhlen M, Oksvold P, Fagerberg L, Lundberg E, Jonasson K, Forsberg M, Zwahlen M, Kampf C, Wester K, Hober S, et al: Towards a knowledge-based human protein atlas. Nat Biotechnol 28: 1248-1250, 2010

30. Durand DB, Shaw JP, Bush MR, Replogle RE, Belagaje R and Crabtree GR: Characterization of antigen receptor response elements within the interleukin-2 enhancer. Mol Cell Biol 8 : $1715-1724,1988$

31. Fang H, Cordoba-Rodriguez R, Lankford CS and Frucht DM: Anthrax lethal toxin blocks MAPK kinase-dependent IL-2 production in CD4+ T cells. J Immunol 174: 4966-4971, 2005.

32. Palmgren MG and Nissen P: P-type ATPases. Annu Rev Biophys 40: 243-266, 2011.

33. van Veen S, Sørensen DM, Holemans T, Holen HW, Palmgren MG and Vangheluwe P: Cellular function and pathological role of ATP13A2 and related P-type transport ATPases in Parkinson's disease and other neurological disorders. Front Mol Neurosci 7: 48, 2014.

34. Brunori M, Antonini G, Malatesta F, Sarti P and Wilson MT: Cytochrome- $c$ oxidase. Subunit structure and proton pumping. Eur J Biochem 169: 1-8, 1987.

35. Chung MC, Narayanan A, Popova TG, Kashanchi F, Bailey CL and Popov SG: Bacillus anthracis derived nitric oxide induces protein S-nitrosylation contributing to macrophage death. Biochem Biophys Res Commun 430: 125-130, 2013.

36. Harada T, Iwai A and Miyazaki T: Identification of DELE, a novel DAP3-binding protein which is crucial for death receptor-mediated apoptosis induction. Apoptosis 15: 1247-1255, 2010.

37. Morinaga T, Enomoto A, Shimono Y, Hirose F, Fukuda N, Dambara A, Jijiwa M, Kawai K, Hashimoto K, Ichihara M, et al: GDNF-inducible zinc finger protein 1 is a sequence-specific transcriptional repressor that binds to the HOXA10 gene regulatory region. Nucleic Acids Res 33: 4191-4201, 2005.

38. Brown RS, Sander C and Argos P: The primary structure of transcription factor TFIIIA has 12 consecutive repeats. FEBS Lett 186: 271-274, 1985

39. Xie T, Sun C, Uslu K, Auth RD, Fang H, Ouyang W and Frucht DM: A new murine model for gastrointestinal anthrax infection. PloS One 8: e66943, 2013.

40. Burgos R: Isolation of interacting peptides to Bacillus anthracis lethal toxin (LF) by T7 phage display (unpublished Master's dissertation). University of Puerto Rico, 2010. 